\title{
Renovation and Reuse of Reactive Dyeing Effluent by a Novel Heterogeneous Fenton System Based on Metal Modified PTFE Fibrous Catalyst $/ \mathbf{H}_{2} \mathbf{O}_{2}$
}

\author{
Bing Li, ${ }^{1}$ Yongchun Dong, ${ }^{1,2}$ Zhizhong Ding, ${ }^{2}$ Yiming Xu, ${ }^{1}$ and Chi Zou ${ }^{1}$ \\ ${ }^{1}$ Textile Chemistry \& Ecology, School of Textiles, Tianjin Polytechnic University, Tianjin 300387, China \\ ${ }^{2}$ Key Laboratory of Advanced Textile Composite of Ministry of Education, Tianjin Polytechnic University, Tianjin 300387, China
}

Correspondence should be addressed to Yongchun Dong; dye@tjpu.edu.cn

Received 10 July 2013; Revised 4 October 2013; Accepted 4 October 2013

Academic Editor: Mika Sillanpaa

Copyright (C) 2013 Bing Li et al. This is an open access article distributed under the Creative Commons Attribution License, which permits unrestricted use, distribution, and reproduction in any medium, provided the original work is properly cited.

$\mathrm{Cu}$-Fe bimetallic grafted polytetrafluoroethylene (PTFE) fiber complexes were prepared and optimized as the novel heterogeneous Fenton catalysts for the degradation of reactive dyes under UV irradiation. Cotton fabrics were dyed with three reactive dyes, namely, Reactive Red 195, Reactive Yellow 145, and Reactive Blue 222, in tap fresh water using exhaustion process. The spent dyeing effluents were then collected and degraded with the optimized Cu-Fe bimetallic grafted PTFE fiber complex/ $\mathrm{H}_{2} \mathrm{O}_{2}$ system. The treated dyeing effluents were characterized and reused for the dyeing of cotton fabrics through the same process. The effect of reuse process number on quality of the dyed cotton fabrics was examined. The results indicated that the $\mathrm{Cu}$-Fe bimetallic modified PTFE fiber complex with a $\mathrm{Cu} / \mathrm{Fe}$ molar ratio of 2.87 was found to be the most effective fibrous catalyst, which enhanced complete decolorization of the treated dyeing effluents with $\mathrm{H}_{2} \mathrm{O}_{2}$ in $4 \mathrm{~h}$. However, the TOC removal for the treated dyeing effluents was below $80 \%$. The dyeing quality was not affected for three successive cycles. The increase in residual TOC value influences fourth dyeing cycle. Further TOC reduction of the treated effluents is needed for its repeated reuse in more than three dyeing cycles.

\section{Introduction}

Textile dyeing is a significant consumer of water and producer of contaminated aqueous waste streams because textile dyeing processes are generally conducted in water-based dyeing baths and the dyeing processes require the addition of colorants and inorganic salts as dyeing promoter or retardant. In a typical dyeing factory, about $0.2-0.5 \mathrm{~m}^{3}$ of water is needed to produce $1 \mathrm{~kg}$ of finished textiles [1]. Dyeing wastewaters are known to present strong color and high COD values since more than $15 \%$ of the textile dyes are generally lost in wastewater stream during dyeing operation. It is a well-known fact that reactive dyes have become one of the major classes of colorants for dyeing of cellulose fiber because over $50 \%$ of cotton products are colored with reactive dyes. Besides, a large amount of salt is usually required when the cellulose fiber is dyed with reactive dyes, which have been one source of pollutant in dyeing wastewater. Moreover, the reactive dye-containing effluent is often persistent and recalcitrant to microbial degradation. In recent years, the increasing cost of water and wastewater treatment as well as government's tighter restrictions on wastewater discharges is forcing textile processors to reuse process water. A better alternative is an attempt at renovating the dyeing wastewater for reuse. Some works have been carried out to examine the possibility of recycling dyeing effluents after decoloration using ozonation, electrochemistry, or Fenton process [2-13]. Ozone has been often used as an effective oxidant for decoloration and reuse of the dyebath water, which can be recycled in reactive or acid dyeing process [2-5]. However, the dyeing quality was sometimes affected by the reuse of decolorized dyebath water, possibly because the corresponding removal of chemical oxygen demand (COD) was not significant [2]. The electrochemical treatment was also used to decolorize the exhausted reactive dyebath and washing effluents, the reuse of which provided excellent red and yellow dyeing textiles $[6,7]$. The oxidation technologies based on $\mathrm{ZnO}[8]$ and $\mathrm{K}_{2} \mathrm{FeO}_{4}$ [9] were applied for dyebath water treatment and recycle. 


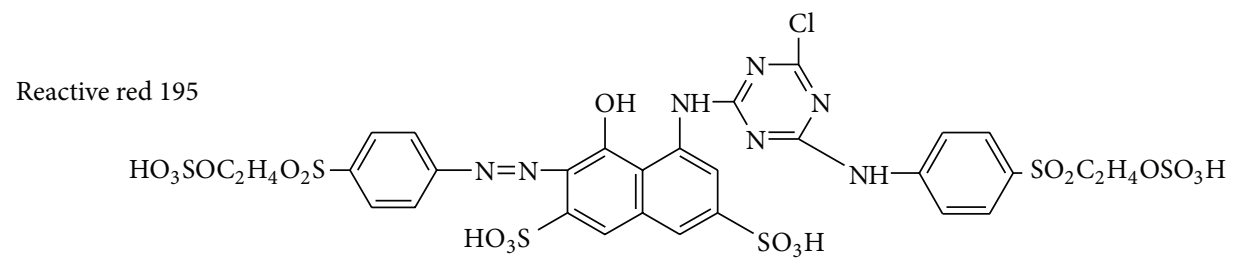

Reactive yellow 145<smiles></smiles>

Reactive blue 222<smiles>[X]O[N+]([O-])(O)c1ccc(Nc2nc(F)nc(Nc3ccc(OS(=O)(=O)[O-])cc3)n2)cc1N=Nc1c([N+](=O)[O-])cc2cc([N+](=O)[O-])c(N=Nc3ccc4c([N+](=O)[O-])cccc4c3S(N)(=O)=O)c(O)c2c1N</smiles>

Scheme 1: Chemical structures of the three dyes.

Fenton and photoassisted Fenton technologies as the important advanced oxidation processes (AOPs) have been widely applied in textile wastewater treatments. But drawbacks in the use of Fenton reactions are found to be the limitation of $\mathrm{pH}$ value and the problem of separation and regeneration at the end of the reaction $[10,11]$. Moreover, Fenton and photoassisted Fenton technologies generally combined with biological processes for textile wastewater treatment and reuse $[12,13]$ and thus, led to higher treating cost. In recent years, the active heterogeneous Fenton catalysis is gradually replacing the homogeneous system by immobilized Fe ions on the polymer substrates. Fe (III)-fiber complexes represent a kind of promising heterogeneous catalysts with unique properties, such as lower cost, easy separation, large surface area, suitable chemical and mechanical stability as well as convenient utility [14-16]. However, very little research has been focused on the treatment and reuse of dyeing wastewater using a heterogeneous Fenton reaction system. The detailed information about the impact of recycling on quality of the dyed fabric is rare for this treating process. In this approach, a series of $\mathrm{Cu}-\mathrm{Fe}$ bimetallic grafted polytetrafluoroethylene (PTFE) fiber complexes was prepared and investigated as the effective heterogeneous Fenton catalysts for renovating and recycling reactive dye effluents for dyeing of cotton fabric. This is because PTFE fiber as the support material has advantages including large specific surface area, excellent chemical and mechanical stability, easy handling, and convenient utility in various forms [17]. Three reactive dyes containing multireactive groups were used for coloration of cotton fabrics by an exhaustion process, due mainly to its relatively high consumption rate in China for the dyeing of cotton textiles.

\section{Experimental}

2.1. Materials and Reagents. Commercially scoured, bleached, and mercerized cotton woven fabric was used in this study. This fabric was further treated with a solution containing $2.0 \mathrm{gL}^{-1} \mathrm{Na}_{2} \mathrm{CO}_{3}$ and $2.0 \mathrm{gL}^{-1}$ soap at the boil for 30 minutes, then thoroughly washed with cold water and dried at ambient temperature. The commercial PTFE fibers were purchased from Fuxin Sengfuli Polymer Materials Co., China. Acrylic acid, $\mathrm{FeCl}_{3} \cdot 6 \mathrm{H}_{2} \mathrm{O}, \mathrm{CuSO}_{4} \cdot 5 \mathrm{H}_{2} \mathrm{O}, \mathrm{H}_{2} \mathrm{O}_{2}(30 \%$, w/w), $\mathrm{Na}_{2} \mathrm{SO}_{4}$, and $\mathrm{Na}_{2} \mathrm{CO}_{3}$ were of analytical grade and all purchased from the Tianjin Nankai Chemicals Co., China. Three commercial grade reactive dyes including Reactive Red 195 (RR 195), Reactive Yellow 145 (RY 145), and Reactive Blue 222 (RB 222) were supplied by Tianjin Sanhuan Chemical Co., China. These dyes were not purified prior to use. Their molecular structures are presented in Scheme 1.

2.2. Reactive Dyeing Procedure. A laboratory dyeing machine with 12 stainless steel dyeing tubes of $500 \mathrm{~mL}$ capacity was used for dyeing. Known weight of pretreated cotton fabric was dyed at $3.0 \%$ shade on weight of fabric (owf) with the dyes selected using a fabric/liquor ratio of $1: 50$ at $60^{\circ} \mathrm{C}$ for $40 \mathrm{~min}$. Dye bath consisted of necessary quantity of reactive 
dye, $40.0 \mathrm{gL}^{-1} \mathrm{Na}_{2} \mathrm{SO}_{4}$, and tap fresh water. After dyeing, the fixation of the adsorbed dye on cotton fabric was conducted at $60^{\circ} \mathrm{C}$ for $30 \mathrm{~min}$ by adding $\mathrm{Na}_{2} \mathrm{CO}_{3}$ into the dyeing bath. The dyed fabric was then removed from the dye bath and squeezed to fall back in the bath itself. Afterwards, the dyed fabrics were rinsed thoroughly using water at the boil for $15 \mathrm{~min}$ and air dried. Finally, the rinsing effluent was collected and mixed with the exhausted dyebath water to form the dyeing wastewater.

\subsection{Preparation of Metal Modified PTFE Fibrous Catalysts}

2.3.1. Graft Polymerization of PTFE Fibers. According to the literatures [18], 5.0 $\mathrm{g}$ of the dried PTFE fibers was immersed into the monomer solution containing $50 \mathrm{~mL}$ acrylic acid and $100 \mathrm{~mL}$ deionized water in a $250 \mathrm{~mL}$ flask. Ammonium ferrous sulphate $(3.0 \mathrm{wt} \%)$ was also used in the monomer solution to minimize the homopolymerization of acrylic acid during the reaction. The flask containing the monomer solution and fibers was bubbled with nitrogen to remove oxygen and was sealed. The mixture in the flask was directly subjected to gamma rays of irradiation from a ${ }^{60} \mathrm{Co}$ source at a dose rate of $0.5 \mathrm{kGyh}^{-1}$ for the given time. After irradiation, the grafted PTFE fibers (denoted as PAA-g-PTFE) were taken out, washed with hot water and acetone repeatedly and dried in a vacuum oven at $50^{\circ} \mathrm{C}$ for $24 \mathrm{~h}$, and weighed. The grafting degree of PTFE fibers was determined by the percentage increase in weight to be $36.48 \%$.

2.3.2. Metal PAA-g-PTFE Complexes. Five grams of PAA-gPTFE was placed into $150 \mathrm{~mL}$ of mixed metal salt aqueous solutions of $\mathrm{FeCl}_{3}$ and $\mathrm{CuSO}_{4}$. In all cases, the concentrations of the total metal ions were kept constant at $0.10 \mathrm{molL}^{-1}$. The mixture was then treated at $50^{\circ} \mathrm{C}$ and $\mathrm{pH} 2-3$ for the given time under continuous agitation. The resulting fibrous metal complexes were filtered, washed with deionized water, and dried under vacuum at $60^{\circ} \mathrm{C}$ for $4.0 \mathrm{~h}$ to obtain $\mathrm{Fe}$ grafted PTFE fiber complex (denoted as Fe-PAA-g-PTFE), Cu grafted PTFE fiber complex (denoted as Cu-PAA-g-PTFE), and $\mathrm{Cu}-\mathrm{Fe}$ bimetal grafted PTFE fiber complex (Cu-Fe-PAAg-PTFE). The residual concentrations of Fe (III) and $\mathrm{Cu}$ (II) ions in the solutions after coordination were determined using a WXF120 atomic absorption spectrometry (Beijing Rayleigh Analytical Instrument Corp., China) for calculating the Fe content $\left(\mathrm{Q}_{\mathrm{Fe}}\right)$ and $\mathrm{Cu}$ content $\left(\mathrm{Q}_{\mathrm{Cu}}\right)$ of the complexes, respectively.

2.4. Treatment and Recycle of Dyeing Effluent. The treating system of dyeing effluent included filtration, degradation, and active carbon fiber adsorption units. The dyeing effluent was firstly filtrated to remove the fiber tows for obtaining a better degradation. The dyeing effluent was degraded at room temperature for the given time using a photoreaction system consist mainly of chamber, UV lamp ( $400 \mathrm{~W}, 365 \mathrm{~nm}$ ), electromagnetic valve, relay, water bath, and reaction vessels. The schematic diagram of the photoreaction system was presented in our previous works [14, 16]. PAA-g-PTFE complex was firstly fixed on small glass rack and then placed into the

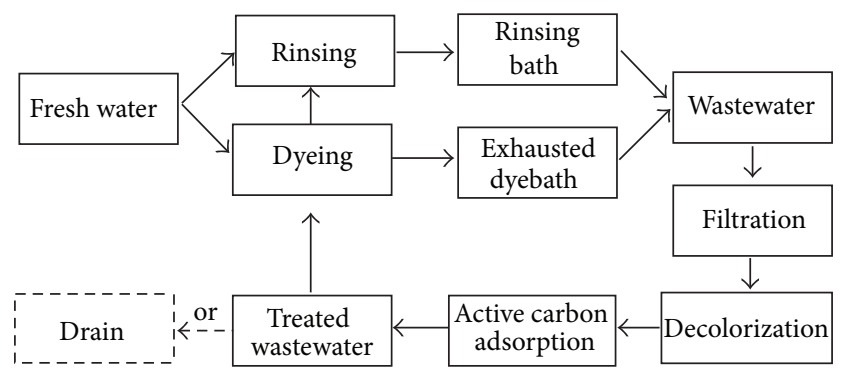

FIGURE 1: Schematic of degradation and reuse processes of reactive dyeing effluent.

mixing solution of dyeing effluent and $\mathrm{H}_{2} \mathrm{O}_{2}$ in reaction vessels. The $\mathrm{pH}$ of the solution was adjusted with $0.10 \mathrm{mmolL}^{-1}$ $\mathrm{HNO}_{3}$ and/or $\mathrm{NaOH}$ aqueous solution and measured using DHS-25C digital pH meter (Shanghai Jingmi Instrumental Co., China). Afterwards, the treated dyeing effluent was further purified by the active carbon fibers (BET specific surface area: $800-2000 \mathrm{~m}^{2} \mathrm{~g}^{-1}$ ) and then characterized for $\mathrm{pH}$ value, electric conductivity, color, and total organic carbon (TOC) value according to standard methods. Color of the dyeing effluent was determined by the absorbance measurements using UV-2401 Shimadzu spectrophotometer at the $\lambda_{\max }$ of each dye or $500 \mathrm{~nm}$ for the real dyeing effluent. The decoloration percentage of the dye was expressed using

$$
D \%=\frac{C_{0}-C}{C_{0}} \times 100 \%,
$$

where $C_{0}$ and $C$ are the initial and residual concentrations of the dye $\left(\mathrm{mgL}^{-1}\right)$, respectively. Meanwhile, TOC value was measured in the process using a Phoenix 8000 TOC analyzer (Tekmar-Dehrmann Inc., USA), and the TOC removal percentage of the dye was calculated by

$$
\text { TOC removal }(\%)=\frac{\mathrm{TOC}_{0}-\mathrm{TOC}_{t}}{\mathrm{TOC}_{0}} \times 100 \%,
$$

where $\mathrm{TOC}_{0}$ and $\mathrm{TOC}_{t}$ are the TOC values $\left(\mathrm{mgL}^{-1}\right)$ at reaction times 0 and $t$, respectively. When the treated effluents were reused, the same dyeing procedure given above was employed through adjusting the concentration of sodium sulfate to $40.0 \mathrm{gL}^{-1}$ in the dyeing bath, and the dyed samples were assessed for their quality. A schematic of the methodology for degradation and reuse of reactive dyeing effluent is depicted in Figure 1.

2.5. Evaluation of Dyed Cotton Fabrics. Color strength $(K / S)$ of the dyed fabric was established with the aid of KubelkaMunk equation:

$$
\frac{K}{S}=\frac{(1-R)^{2}}{2 R},
$$

where $R$ = fraction of light reflected, $K=$ absorption coefficient, and $S=$ scattering coefficient.

A Datacolor International SF-600 spectrophotometer interfaced to a personal computer under D65 illuminant, using 
TABLE 1: Effect of $\mathrm{Cu} / \mathrm{Fe}$ ratio on decoloration of three reactive dyes.

\begin{tabular}{|c|c|c|c|c|c|c|c|}
\hline \multirow{2}{*}{ Samples } & \multicolumn{3}{|c|}{ Metal content $\left(\mathrm{mmol} \mathrm{L}^{-1}\right)$} & \multirow{2}{*}{$\mathrm{Cu} / \mathrm{Fe}$} & \multicolumn{3}{|c|}{$D_{180} \%$} \\
\hline & $Q_{\mathrm{Fe}}$ & $Q_{\mathrm{Cu}}$ & Total & & RR195 & RY145 & RB222 \\
\hline Fe-PAA-g-PTFE & 1.89 & 0.00 & 1.89 & 0 & 47.31 & 45.67 & 43.75 \\
\hline Cu-Fe-PAA-g-PTFE (i) & 1.13 & 0.75 & 1.88 & 0.66 & 61.22 & 58.80 & 57.93 \\
\hline Cu-Fe-PAA-g-PTFE (ii) & 0.54 & 1.55 & 2.09 & 2.87 & 84.65 & 79.18 & 78.55 \\
\hline Cu-Fe-PAA-g-PTFE (iii) & 0.31 & 1.75 & 2.06 & 5.65 & 78.47 & 73.67 & 72.85 \\
\hline Cu-PAA-g-PTFE & 0.00 & 1.98 & 1.98 & 1 & 51.90 & 45.79 & 44.86 \\
\hline
\end{tabular}

[dye $]=0.05 \mathrm{mmol} \mathrm{L}^{-1},\left[\mathrm{H}_{2} \mathrm{O}_{2}\right]=6.0 \mathrm{mmol} \mathrm{L}^{-1}$, catalyst $=5.0 \mathrm{~g} \mathrm{~L}^{-1}, \mathrm{pH}=6$.

a $10^{\circ}$ standard observer, was used to measure $K / S$ values. The wavelength measured ranged from 400 to $700 \mathrm{~nm}$ with an interval of $10 \mathrm{~nm}$. The greater the $K / S$ value, the greater the coloration of the fabric sample. Then a $K / S$ change percentage $\left(K / S_{\max } \%\right)$ was calculated through

$$
K / S_{\max } \%=\frac{K / S_{\max -2}-K / S_{\max -1}}{K / S_{\max -1}} \times 100 \%,
$$

where $K / S_{\max -1}$ and $K / S_{\max -2}$ are $K / S$ values at the $\lambda_{\max }$ of the dyed fabric using tap fresh water and the treated dyeing effluent, respectively. Moreover, the effect of recycling of treated dyeing water on color reproduction and lightness on cotton fabric was also analyzed using $\mathrm{DE}^{*}$ and $\mathrm{DL}^{*}$ values, respectively, calculated with the help of CIE $\mathrm{L}^{*}, \mathrm{a}^{*}$, and $b^{*}$ (CIELAB) equations. Level dyeing property of the dyed cotton fabric was evaluated by relative unlevelness index (RUI) value calculated using the equation proposed by Senthilkumar and Muthukumar [2]. Color fastness to soaping and rubbing were examined in accordance with Textiles Test Specification for Color Fastness (GB3921.3-1997 and GB3920-1997) based on ISO international standards, which are included in the national standards of China.

\section{Results and Discussion}

3.1. Optimization of Metal Modified PTFE Fibrous Catalyst. Our previous work [19] revealed that Fe modified PTFE fiber complexes acted as an effective heterogeneous Fenton catalyst for the dye degradation under UV or visible irradiation. Moreover, the $\mathrm{Cu}-\mathrm{Fe}$ bimetallic modified PTFE fiber complexes exhibited the excellent catalytic activity because of the existence of synergetic effect between Fe (III) and $\mathrm{Cu}$ (II) ions. In order to meet the demands for rapid and stable dye degradation in future commercial application, a series of $\mathrm{Cu}-\mathrm{Fe}$ bimetal PAA-g-PTFE complexes with different $\mathrm{Cu} / \mathrm{Fe}$ molar ratios were prepared and used in the degradation of the three simulated dyeing effluents containing $0.05 \mathrm{mmol} / \mathrm{L}$ reactive dye studied, respectively. The influence of $\mathrm{Cu} / \mathrm{Fe}$ molar ratio on decoloration percentage of each dye within $180 \min \left(D_{180} \%\right)$ was presented in Table 1.

The data in Table 1 indicate that $D_{180} \%$ value of each dyeing effluent in the presence of the bimetal PAA-g-PTFE complexes is much higher than those in the presence of the monometal PAA-g-PTE complexes, and the maximum $D_{180} \%$ value is achieved for Cu-Fe-PAA-g-PTFE (ii). This

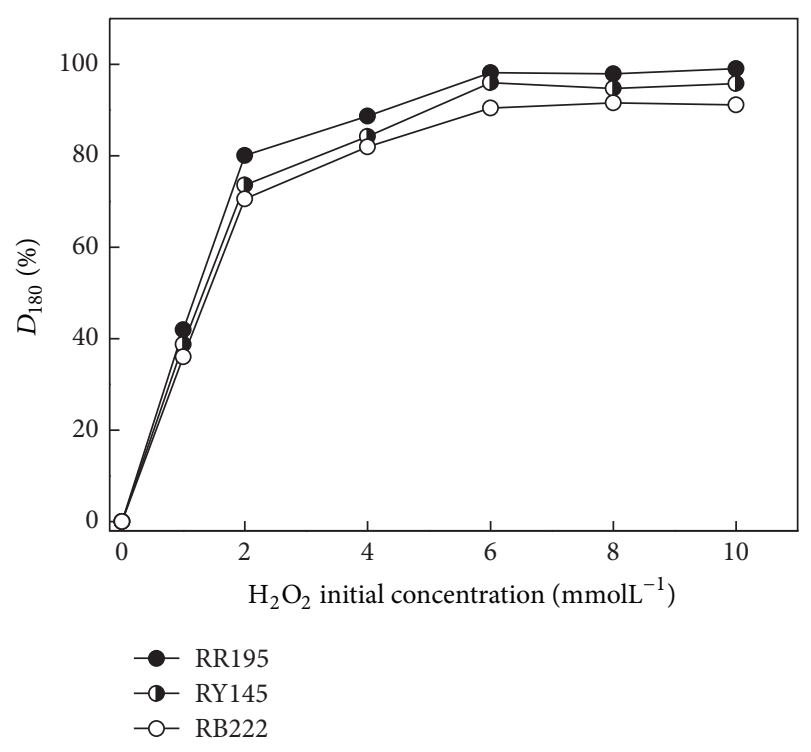

FIGURE 2: Degradation of three dyes with varied initial concentration of $\mathrm{H}_{2} \mathrm{O}_{2}$.

confirms that catalytic activity of metal PAA-g-PTFE complexes depends highly upon their $\mathrm{Cu} / \mathrm{Fe}$ molar ratio, and $\mathrm{Cu}-$ Fe-PAA-g-PTFE (ii) with a $\mathrm{Cu} / \mathrm{Fe}$ molar ratio of 2.87 shows the best catalytic activity at alkaline $\mathrm{pH}$ medium.

3.2. $\mathrm{H}_{2} \mathrm{O}_{2}$ Initial Concentration. The degradation of each reactive dye $\left(0.05 \mathrm{mmolL}^{-1}\right)$ was performed at $\mathrm{pH} 6$ for $180 \mathrm{~min}$ in the presence of $5.0 \mathrm{gL}^{-1} \mathrm{Cu}-\mathrm{Fe}-\mathrm{PAA}-\mathrm{g}-\mathrm{PTFE}$ (ii) and varied $\mathrm{H}_{2} \mathrm{O}_{2}$ initial concentration from 0 to $10.0 \mathrm{mmolL}^{-1}$. The $D_{180} \%$ values of three dyes were shown in Figure 2.

Figure 2 shows that the $D_{180} \%$ values of three dyes gradually increase with increasing $\mathrm{H}_{2} \mathrm{O}_{2}$ initial concentration, and the increasing tendency levels at the concentration of $6.0 \mathrm{mmolL}^{-1}$. Moreover, their $D_{180} \%$ values are higher than $95 \%$ when $\mathrm{H}_{2} \mathrm{O}_{2}$ initial concentration reached $6.0 \mathrm{mmolL}^{-1}$. These results indicate that almost all dye molecules have been degraded under this condition. Accordingly, $6.0 \mathrm{mmolL}^{-1}$ was considered to be the optimum $\mathrm{H}_{2} \mathrm{O}_{2}$ initial concentration for the degradation of $0.05 \mathrm{mmolL}^{-1}$ dye in solution. 


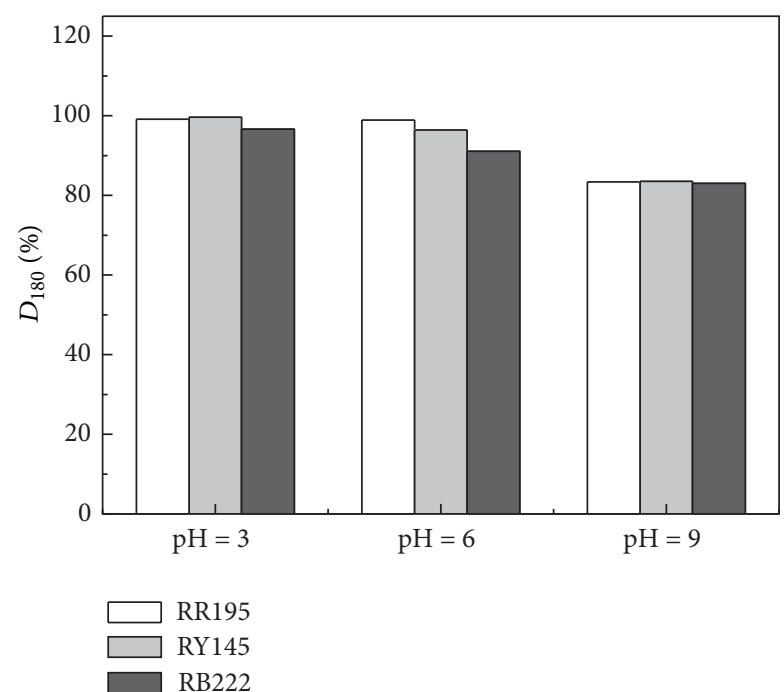

FIgURE 3: Relationship between $\mathrm{pH}$ and $D_{180} \%$ value.

3.3. The Solution $p H$. Some works [20-22] revealed that the heterogeneous Fenton catalysts exhibited the high catalytic function for dye degradation over a wide $\mathrm{pH}$ range. In order to determine the dependence of photocatalytic performance of Cu-Fe-PAA-g-PTFE (ii) on the solution pH, Cu-Fe-PAAg-PTFE (ii) and $\mathrm{H}_{2} \mathrm{O}_{2}$ concentration were set at $5.0 \mathrm{gL}^{-1}$ and $6.0 \mathrm{mmolL}^{-1}$; respectively, the degradation of each dye $\left(0.05 \mathrm{mmolL}^{-1}\right)$ was then conducted for $180 \mathrm{~min}$ at different $\mathrm{pH}$ levels, and the relationship between $\mathrm{pH}$ and $D_{180} \%$ value were given in Figure 3.

Figure 3 shows that $D_{180} \%$ values at $\mathrm{pH} 3$ and 6 are much higher than those at $\mathrm{pH} 9$ for all the dyes. These results demonstrated that $\mathrm{Cu}-\mathrm{Fe}-\mathrm{PAA}-\mathrm{g}$-PTFE (ii) showed excellent catalytic performance at acid medium. It should be noticed that the decreased $D_{200} \%$ values were observed for all the dyes; however, their $D_{180} \%$ values were still over $75 \%$ at $\mathrm{pH} 9$. This proved that $\mathrm{Cu}-\mathrm{Fe}-\mathrm{PAA}-\mathrm{g}-\mathrm{PTFE}$ (ii) could significantly accelerate the dye degradation in a broad $\mathrm{pH}$ range, which is similar to the photocatalytic activity of the heterogeneous photocatalysts such as Fe alginate gel bead [20] and bimetallic $\mathrm{Cu} / \mathrm{Fe}$ clay [22].

3.4. Influence of Sodium Sulfate on Dye Degradation. In order to accelerate absorption of reactive dyes onto cotton fibers in water, $\mathrm{Na}_{2} \mathrm{SO}_{4}$ are often used as the promoters in the dyeing of cotton fabrics with reactive dyes [1]. However, the addition of $\mathrm{Na}_{2} \mathrm{SO}_{4}$ in the dyebath may have an effect on dyeing effluent treatment processes. Hence, the degradation of the three simulated dyeing effluents containing $0.05 \mathrm{mmolL}^{-1}$ reactive dye studied using $\mathrm{Cu}$-Fe-PAA-g-PTFE (ii)/ $/ \mathrm{H}_{2} \mathrm{O}_{2}$ system was carried out in the presence or absence of $\mathrm{Na}_{2} \mathrm{SO}_{4}$, and the results were shown in Figure 4.

Figure 4 shows that $D \%$ and TOC removal (\%) values of each dye increase with the prolonging of reaction time. It should be noticed that the addition of $\mathrm{Na}_{2} \mathrm{SO}_{4}$ leads to little reduction in $D \%$ and TOC removal (\%) for all the dyes, suggesting that the degradation of the reactive dyes

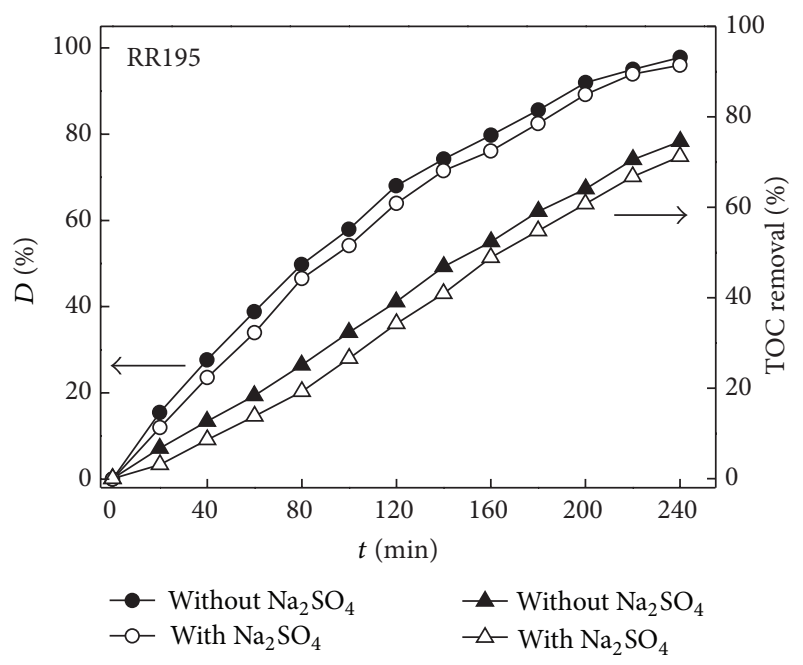

(a)

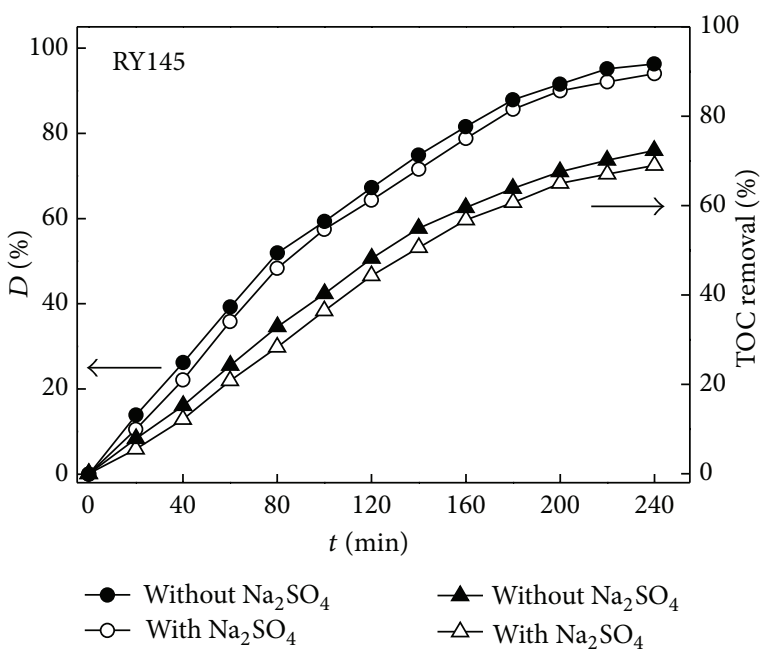

(b)

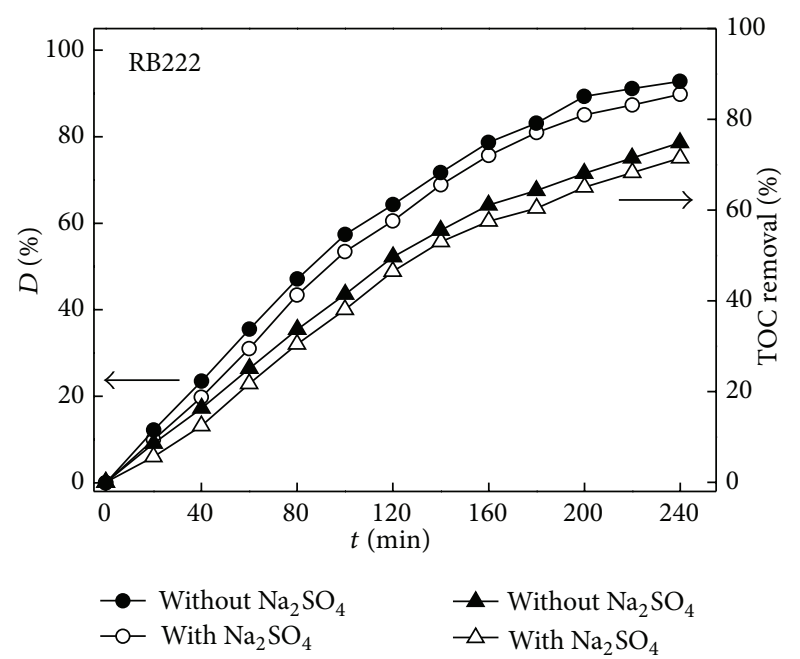

(c)

FigURE 4: Effect of $\mathrm{Na}_{2} \mathrm{SO}_{4}$ on degradation of three reactive dyes ([dye] $=0.05 \mathrm{mmolL}^{-1},\left[\mathrm{H}_{2} \mathrm{O}_{2}\right]=6.0 \mathrm{mmolL}^{-1}$, catalyst $=5.0 \mathrm{gL}^{-1}$, $\left[\mathrm{Na}_{2} \mathrm{SO}_{4}\right]=10.05 \mathrm{gL}^{-1}, \mathrm{pH}=6$ ). 
TABLE 2: Characteristics of raw and decolorized dyeing wastewater.

\begin{tabular}{|c|c|c|c|c|}
\hline $\begin{array}{l}\text { Numbers of } \\
\text { recycling processes }\end{array}$ & Parameters & Raw wastewater & Treated wastewater & Removal \% \\
\hline \multirow{4}{*}{ First } & $\mathrm{pH}$ & 8.48 & 6.22 & 1 \\
\hline & Color (Abs) & 0.502 & 0.008 & 98.41 \\
\hline & Conductivity $\left(\mathrm{mscm}^{-1}\right)$ & 21.91 & 22.87 & -4.38 \\
\hline & $\operatorname{TOC}\left(\mathrm{mg} \mathrm{L}^{-1}\right)$ & 92.97 & 22.88 & 75.38 \\
\hline \multirow{4}{*}{ Second } & $\mathrm{pH}$ & 8.61 & 6.09 & I \\
\hline & Color (Abs) & 0.522 & 0.009 & 98.27 \\
\hline & Conductivity $\left(\mathrm{mscm}^{-1}\right)$ & 23.55 & 25.19 & -6.96 \\
\hline & $\mathrm{TOC}\left(\mathrm{mg} \mathrm{L}^{-1}\right)$ & 104.2 & 38.02 & 63.51 \\
\hline \multirow{4}{*}{ Third } & $\mathrm{pH}$ & 8.78 & 7.02 & 1 \\
\hline & Color (Abs) & 0.533 & 0.010 & 98.12 \\
\hline & Conductivity $\left(\mathrm{mscm}^{-1}\right)$ & 25.18 & 27.09 & -7.60 \\
\hline & TOC $\left(\mathrm{mg} \mathrm{L}^{-1}\right)$ & 112.1 & 47.74 & 57.41 \\
\hline \multirow{4}{*}{ Fourth } & $\mathrm{pH}$ & 8.52 & 7.34 & I \\
\hline & Color (Abs) & 0.538 & 0.011 & 97.95 \\
\hline & Conductivity $\left(\mathrm{mscm}^{-1}\right)$ & 29.35 & 32.38 & -10.32 \\
\hline & $\operatorname{TOC}\left(\mathrm{mg} \mathrm{L}^{-1}\right)$ & 126.1 & 69.09 & 45.22 \\
\hline
\end{tabular}

The absorbance (Abs) at $500 \mathrm{~nm}$ is used to evaluate the color of real dyeing effluent. Color removal \% equals $D \%$ value for real dyeing effluent.

is almost not affected by $\mathrm{Na}_{2} \mathrm{SO}_{4}$ in aqueous solution. This may be due to the two competing factors. On one hand, it is obvious that the presence of salt can increase the aggregation degree of ionic dyes in water, inhabiting the dye degradation [23].On the other hand, the reaction between sulfate ions and hydroxyl radical produced by photo-Fenton reaction can generate the higher oxidative sulphate radicals, which increase the dye degradation efficiency [24].

3.5. Treatment of Real Reactive Dyeing Effluents. The raw reactive dyeing effluents from coloration processes mentioned above were characterized with respect to $\mathrm{pH}$, electric conductivity, color, and TOC values prior to any treatment and then treated using successive filtration, degradation, and active carbon adsorption units presented in Figure 1. The degradation process was conducted using a heterogeneous Fenton system consisting of $\mathrm{Cu}-\mathrm{Fe}-\mathrm{PAA}-\mathrm{g}-$ PTFE (ii) and $\mathrm{H}_{2} \mathrm{O}_{2}$. The optimal conditions were determined as follows: Cu-Fe-PAA-g-PTFE (ii), $5.0 \mathrm{gL}^{-1} ; \mathrm{H}_{2} \mathrm{O}_{2}$ concentration, $6.0 \mathrm{mmolL}^{-1}$; degradation duration, $4.0 \mathrm{~h}$, based on the results of optimization experiments. More importantly, our previous work [25] reported that the used $\mathrm{Cu}-\mathrm{Fe}-\mathrm{PAA}-\mathrm{g}-\mathrm{PTFE}$ (ii) could be reused five times by thorough wash with mixed solution of $50 / 50(\mathrm{v} / \mathrm{v}) \%$ water and ethanol under ultrasonication. The reason is that this photocatalyst was developed with the intention of (a) withstanding the corrosion due to the oxidative radicals produced in solution and (b) fixing the metal ions on a support in a stable way so as not to allow them to leach out during the reaction. The treated effluent was reused for the dyeing of cotton fabric after the characterization. The quality of the raw and treated effluents after different recycling processes was summarized in Table 2.
It is evident from the data in Table 2 that the color removals of more than $97 \%$ for the dyeing effluents from different recycling processes can be obtained after the treatment. However, the TOC removals of the treated dyeing effluents gradually decrease as the number of recycling processes increases. This suggests that although the dyeing effluents can be almost completely decolorized using $\mathrm{Cu}$-Fe-PAA-g-PTFE (ii) $/ \mathrm{H}_{2} \mathrm{O}_{2}$ system, the mineralization of the dye molecules in the effluents is limited possibly due to the partial oxidation of organic substrates. Similar results have been reported in the ozonation treatment of reactive and acid dyeing wastewaters $[2,4]$. It is observed from Table 2 that their $\mathrm{pH}$ value and electric conductivity increase with the increasing number of recycling processes. This is attributed mainly to fact that addition of $\mathrm{Na}_{2} \mathrm{SO}_{4}$ and $\mathrm{Na}_{2} \mathrm{CO}_{3}$ during the recycling. It should be noted that $\mathrm{pH}$ values decline after the treatment for all the wastewaters from the recycling processes. This may be owing to the generation of acidic by-products during the oxidation makes the effluent acidic in nature [26]. Additionally, the treatment leads to higher conductivity, indicating that inorganic salt concentration increases in the treated effluent because of the partial mineralization of the dyes in water.

3.6. Evaluation of Dyeing Quality. The quality of the cotton fabrics dyed with three reactive dyes using the treated dyeing effluent was evaluated with respect to their color strength, color difference, fastness, and leveling properties, respectively. The effect of recycling process on the dyeing quality was then examined in order to assess the color reproduction in the treated dyeing effluent. Consequently, the dyeing of cotton fabrics using tap fresh water was regarded as the control experiment, and the resulting dyed cotton fabric in the control experiment 


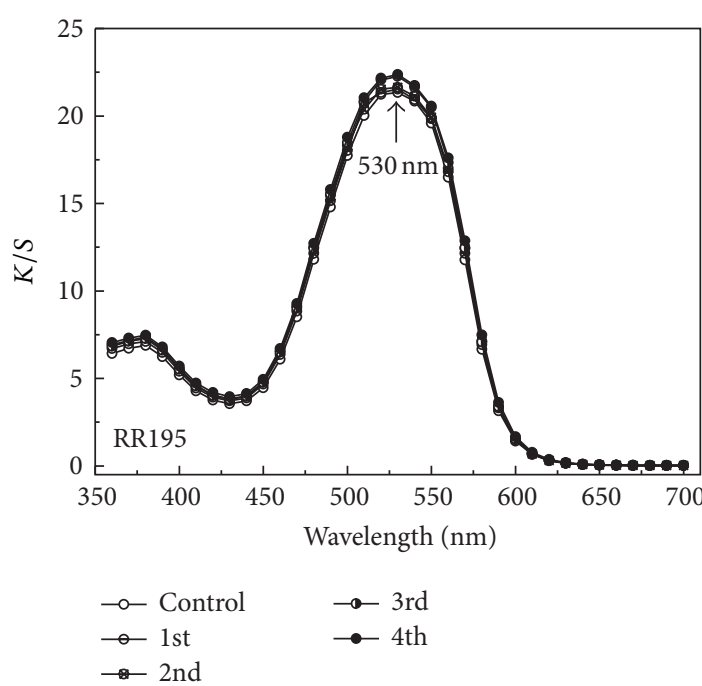

(a)

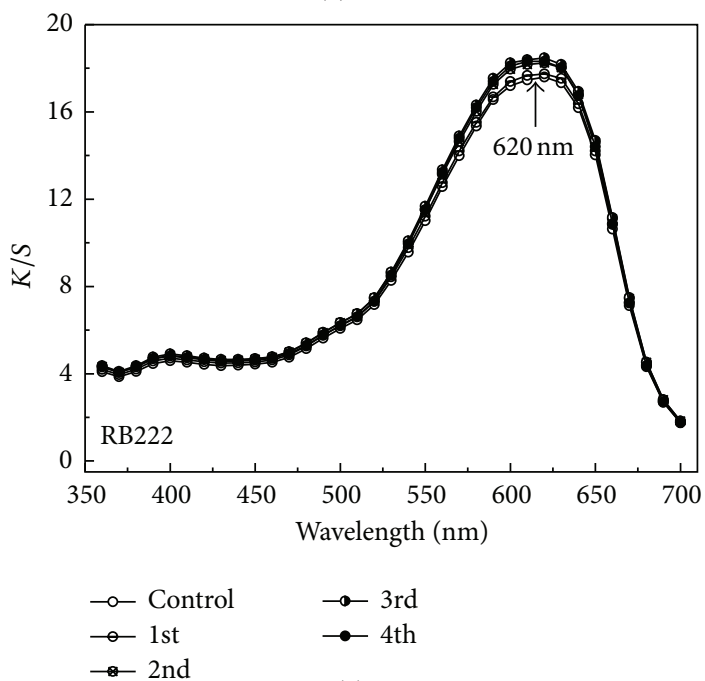

(c)

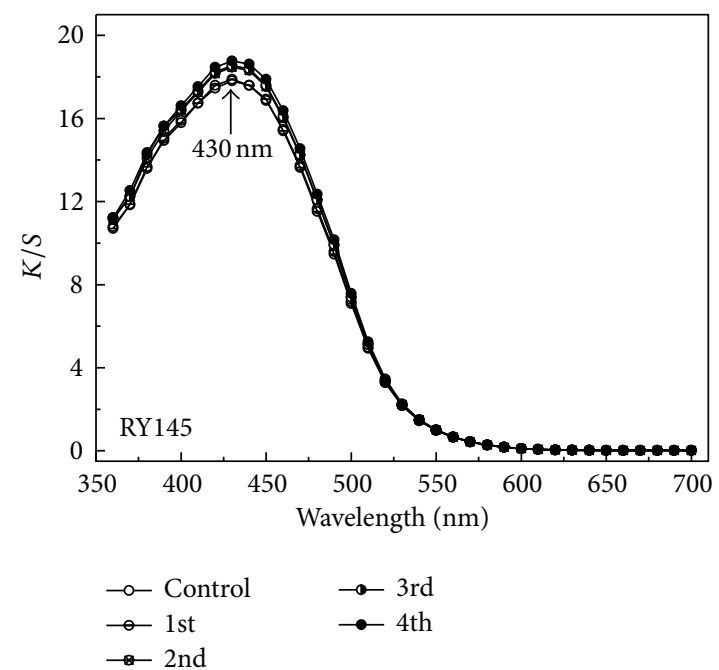

(b)

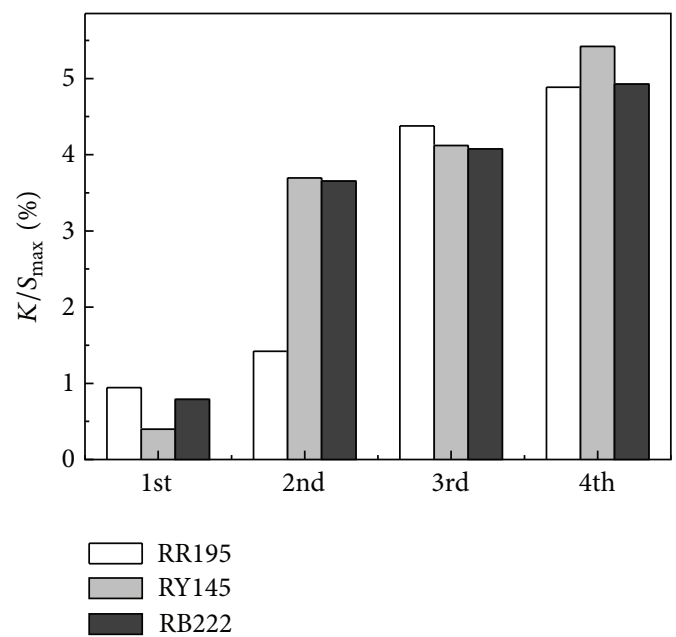

(d)

Figure 5: $K / S$ curves and $K / S_{\max } \%$ values of three dyed cotton fabrics compared to control samples.

was used as the control sample, by which dyeing reproducibility was judged.

3.6.1. Color Strength. $K / S$ curves and $K / S_{\max } \%$ values of the dyed cotton fabrics obtained from various recycling processes and the control experiments were measured and calculated; the experimental results were presented in Figure 5.

It is found, from Figure 5, that $K / S$ curves of the dyed cotton fabrics in the recycling processes, especially the first and second recycling processes are similar to those of the control samples. The $K / S_{\max } \%$ values of the samples dyed with three reactive dyes, particularly RY 145 and RB 222, significantly increase with the increasing number of recycling processes. In the case of RY 145 , the $K / S_{\max } \%$ value of the dyed sample is slightly more than $5.0 \%$ in the fourth recycling, implying that dyeing with RY 145 using the treated effluent is limited in fourth recycling.
3.6.2. Color Differences. The $\mathrm{DE}^{*}, \mathrm{DL}^{*}, \mathrm{Da}^{*}, \mathrm{Db}^{*}, \mathrm{DC}^{*}$, and $\mathrm{DH}^{*}$ values of three dyed cotton fabrics produced from different recycling processes are given in Table 3.

It is clear, from Table 3, that, for three reactive dyes, the $\mathrm{DE}^{*}$ values of the dyed fabrics became higher with the increasing number of recycling processes, while their $\mathrm{DL}^{*}$ values exhibit a reverse trend. This proposes that the dyed fabrics produced by recycling processes become gradually darker in shade compared with the control samples because of their negative $\mathrm{DL}^{*}$ values. This may be mainly attributed to the insignificant variation in inorganic salt concentration and $\mathrm{pH}$ level of the treated dyeing effluents. The dyed fabrics are generally acceptable when the $\mathrm{DE}^{*}$ values are between 0 and 1.5 and the $\mathrm{DL}^{*}$ values are between -0.7 and 0.4 . If the $\mathrm{DL}^{*}$ values are less than -0.7 , the samples are darker in shade, and if they are greater than 0.4 the samples are lighter in shade compared to that of control sample [2]. Therefore, as seen from Table 3, in the case of RR 195 and RY 145, 
TABLE 3: Color differences of three dyed fabrics with respect to control samples.

\begin{tabular}{|c|c|c|c|c|c|c|c|}
\hline Dyes & $\begin{array}{c}\text { Numbers of } \\
\text { recycling processes }\end{array}$ & $\mathrm{DE}^{*}$ & $\mathrm{DL}^{*}$ & $\mathrm{Da}^{*}$ & $\mathrm{Db}^{*}$ & $\mathrm{DC}^{*}$ & $\mathrm{DH}^{*}$ \\
\hline \multirow{4}{*}{ RR 195} & First & 0.475 & 0.343 & 0.121 & -0.306 & 0.078 & -0.320 \\
\hline & Second & 0.525 & -0.182 & -0.263 & 0.417 & -0.205 & 0.448 \\
\hline & Third & 0.863 & -0.584 & -0.012 & 0.635 & 0.074 & 0.631 \\
\hline & Fourth & 1.301 & -0.551 & -0.265 & 1.148 & -0.102 & 1.174 \\
\hline \multirow{4}{*}{ RY 145} & First & 0.112 & -0.039 & 0.103 & 0.018 & 0.062 & -0.084 \\
\hline & Second & 0.213 & -0.034 & -0.007 & 0.210 & 0.188 & 0.094 \\
\hline & Third & 0.681 & -0.046 & -0.101 & -0.672 & -0.653 & -0.188 \\
\hline & Fourth & 0.680 & -0.265 & 0.608 & 0.151 & 0.411 & -0.473 \\
\hline \multirow{4}{*}{ RB 222} & First & 0.241 & -0.216 & -0.108 & -0.007 & 0.028 & -0.105 \\
\hline & Second & 0.583 & -0.497 & 0.04 & 0.303 & -0.305 & -0.022 \\
\hline & Third & 0.963 & -0.879 & 0.106 & 0.379 & -0.393 & 0.033 \\
\hline & Fourth & 0.995 & -0.954 & 0.002 & 0.285 & -0.280 & -0.053 \\
\hline
\end{tabular}

The control samples were regarded as the references.

TABLE 4: Relative unlevelness index (RUI) values of dyed samples.

\begin{tabular}{lccc}
\hline Dyed samples & Reactive red 195 & Reactive yellow 145 & Reactive blue 222 \\
\hline Control & 0.022 & 0.030 & 0.033 \\
First recycle & 0.046 & 0.055 & 0.052 \\
Second recycle & 0.067 & 0.081 & 0.070 \\
Third recycle & 0.091 & 0.099 & 0.102 \\
Fourth recycle & 0.137 & 0.158 & 0.149 \\
\hline
\end{tabular}

RUI values: $<0.2$ (excellent levelness), 0.2-0.49 (good levelness), 0.5-1.0 (poor levelness), and >1.0 (bad levelness) [2].

the $\mathrm{DE}^{*}$ and $\mathrm{DL}^{*}$ values fall in acceptable limits for all the recycling process, suggesting that recycled effluents can be used four times; whereas, for RB 222, the $\mathrm{DE}^{*}$ values are accepted in all the recycles; however, the $\mathrm{DL}^{*}$ values are lower than -0.7 in the last two recycling processes. This reveals that the recycled effluents can be used only two times for RB 222, which may be attributed to increasing amount of the intermediates formed during Fenton-treatment in third and fourth recycling processes. Also this mainly stems from the difference in the dyeing characteristics and molecular structure between these reactive dyes.

3.6.3. Level Dyeing Character. In order to accurately examine the levelness of the dyed cotton fabrics obtained from various recycling processes and control experiments, their RUI index were calculated and provided in Table 4.

It is seen from Table 4 that the RUI indexes of the dyed cotton fabrics using the treated effluents are higher than those of control samples, and it shows a gradual increasing trend as the number of recycling processes increases. But these RUI indexes are still accepted according to the relationship between RUI and visual appearance of levelness suggested by Senthilkumar and Muthukumar [2].

3.6.4. Fastness Properties. The soaping fastness and rubbing fastness of the dyed cotton fabrics obtained from various recycling processes and the control experiments were tested and summarized in Table 5.

The data in Table 5 indicate that the increase in number of recycling processes is accompanied by an insignificant reduction in the soaping fastness and rubbing fastness of the dyed cotton fabrics. This demonstrates that the formation of by-products during Fenton reaction may interfere with the fixation of the reactive dye on cellulose fiber during the dyeing procedure, thus, causing the insignificant reduction in color fastness. However, it is believed that the soaping fastness and rubbing fastness of the dyed cotton fabrics using the treated dyeing effluent as the aqueous medium are still of practical value in the future commercial application.

\section{Conclusions}

The Cu-Fe bimetallic modified PTFE fiber complex with a $\mathrm{Cu} / \mathrm{Fe}$ molar ratio of 2.87 as a novel heterogeneous Fenton photocatalyst was successfully applied in the treatment and reuse of reactive dyeing effluents under UV irradiation. A complete decoloration and relatively high TOC removal can be achieved within $4 \mathrm{~h}$, when this catalyst was used. TOC removal level is mainly dependent on the number of recycling processes. Increasing the number of recycling processes resulted in the dark shade, relatively big color differences, and insignificant deteriorated fastness of the dyed cotton 
TABLE 5: Soaping and rubbing fastness of dyed cotton fabrics in recycling processes.

\begin{tabular}{|c|c|c|c|c|c|}
\hline \multirow{2}{*}{ Dyes } & \multirow{2}{*}{$\begin{array}{c}\text { Numbers of } \\
\text { recycling processes }\end{array}$} & \multicolumn{2}{|c|}{ Soaping fastness } & \multicolumn{2}{|c|}{ Rubbing fastness } \\
\hline & & Staining & Fading & Dry & Wet \\
\hline \multirow{5}{*}{ Reactive red 195} & Control & $4-5$ & $4-5$ & $4-5$ & $4-5$ \\
\hline & First & $4-5$ & $4-5$ & $4-5$ & $4-5$ \\
\hline & Second & $4-5$ & 4 & $4-5$ & 4 \\
\hline & Third & $4-5$ & 4 & 4 & 4 \\
\hline & Fourth & 4 & 4 & 4 & 4 \\
\hline \multirow{5}{*}{ Reactive yellow 145} & Control & $4-5$ & $4-5$ & $4-5$ & $4-5$ \\
\hline & First & $4-5$ & $4-5$ & $4-5$ & $4-5$ \\
\hline & Second & $4-5$ & $4-5$ & $4-5$ & 4 \\
\hline & Third & $4-5$ & 4 & $4-5$ & 4 \\
\hline & Fourth & 4 & 4 & 4 & 4 \\
\hline \multirow{5}{*}{ Reactive blue 222} & Control & $4-5$ & $4-5$ & $4-5$ & 4 \\
\hline & First & $4-5$ & $4-5$ & $4-5$ & 4 \\
\hline & Second & $4-5$ & $4-5$ & $4-5$ & 4 \\
\hline & Third & $4-5$ & $4-5$ & $4-5$ & 4 \\
\hline & Fourth & 4 & 4 & 4 & 4 \\
\hline
\end{tabular}

fabrics using the treated dyeing effluence compared to those of control samples. Quality of the dyeing effluents treated by the resulting catalyst could comply with the criteria of water quality for reuse in the reactive dyeing processes. The number of recycled effluents is found to be highly determined by quality of the treated dyeing effluent and dyeing properties of the reactive dyes used. It should be pointed out that the TOC removal for treated dyeing effluents was below $60 \%$ except first two recycling processes. The impact of the significant increase in residual TOC value on fourth dyeing cycle suggests that this novel heterogeneous Fenton catalyst is feasible for decolorizing reactive dyebath waters for third cycle of reuse. Further TOC reduction of the treated dyeing effluent is needed for its repeated reuse in more than three dyeing cycles.

\section{Acknowledgments}

The authors thank the Tianjin Municipal Science and Technology Committee for a Research Program of Application Foundation and Advanced Technology (11JCZDJ24600). This research was also supported in part by a Grant from the Natural Science Foundation of China (20773093).

\section{References}

[1] S. Yi, Y. Dong, B. Li, Z. Ding, X. Huang, and L. Xue, "Adsorption and fixation behaviour of CI Reactive Red 195 on cotton woven fabric in a nonionic surfactant Triton X-100 reverse micelle," Coloration Technology, vol. 128, no. 4, pp. 306-314, 2012.

[2] M. Senthilkumar and M. Muthukumar, "Studies on the possibility of recycling reactive dye bath effluent after decolouration using ozone," Dyes and Pigments, vol. 72, no. 2, pp. 251$255,2007$.
[3] M. Sundrarajan, G. Vishnu, and K. Joseph, "Ozonation of lightshaded exhausted reactive dye bath for reuse," Dyes and Pigments, vol. 75, no. 2, pp. 273-278, 2007.

[4] S. V. Srinivasan, T. Rema, K. Chitra et al., "Decolourisation of leather dye by ozonation," Desalination, vol. 235, no. 1-3, pp. 8892, 2009.

[5] P. Colindres, H. Yee-Madeira, and E. Reguera, "Removal of Reactive Black 5 from aqueous solution by ozone for water reuse in textile dyeing processes," Desalination, vol. 258, no. 1-3, pp. $154-158,2010$.

[6] N. Mohan, N. Balasubramanian, and C. A. Basha, "Electrochemical oxidation of textile wastewater and its reuse," Journal of Hazardous Materials, vol. 147, no. 1-2, pp. 644-651, 2007.

[7] V. López-Grimau, M. del Carmen Gutiérrez-Bouzán, J. Valldeperas, and M. Crespi, "Reuse of the water and salt of reactive dyeing effluent after electrochemical decolorisation," Coloration Technology, vol. 128, no. 1, pp. 36-43, 2012.

[8] L. S. Roselin and R. Selvin, "Photocatalytic treatment and reusability of textile dyeing effluents from cotton dyeing industries," Science of Advanced Materials, vol. 3, no. 1, pp. 113-119, 2011.

[9] I. Ciabatti, F. Tognotti, and L. Lombardi, "Treatment and reuse of dyeing effluents by potassium ferrate," Desalination, vol. 250, no. 1, pp. 222-228, 2010.

[10] Z. Wang, W. Ma, C. Chen, and J. Zhao, "Light-assisted decomposition of dyes over iron-bearing soil clays in the presence of $\mathrm{H}_{2} \mathrm{O}_{2}$," Journal of Hazardous Materials, vol. 168, no. 2-3, pp. 1246-1252, 2009.

[11] H. Jia, J. Zhao, X. Fan, K. Dilimulati, and C. Wang, "Photodegradation of phenanthrene on cation-modified clays under visible light," Applied Catalysis B, vol. 123, pp. 43-51, 2012. 
[12] F. Feng, Z. Xu, X. Li, W. You, and Y. Zhen, "Advanced treatment of dyeing wastewater towards reuse by the combined Fenton oxidation and membrane bioreactor process," Journal of Environmental Sciences, vol. 22, no. 11, pp. 1657-1665, 2010.

[13] J. Blanco, F. Torrades, M. De la Varga, and J. García-Montaño, "Fenton and biological-Fenton coupled processes for textile wastewater treatment and reuse," Desalination, vol. 286, pp. 394-399, 2012.

[14] X. Liu, R. Tang, Q. He, X. Liao, and B. Shi, "Fe(III)-loaded collagen fiber as a heterogeneous catalyst for the photo-assisted decomposition of Malachite Green," Journal of Hazardous Materials, vol. 174, no. 1-3, pp. 687-693, 2010.

[15] Y. Dong, Z. Han, C. Liu, and F. Du, "Preparation and photocatalytic performance of Fe (III)-amidoximated PAN fiber complex for oxidative degradation of azo dye under visible light irradiation," Science of the Total Environment, vol. 408, no. 10, pp. 2245-2253, 2010.

[16] Z. Han, Y. Dong, and S. Dong, “Copper-iron bimetal modified PAN fiber complexes as novel heterogeneous Fenton catalysts for degradation of organic dye under visible light irradiation," Journal of Hazardous Materials, vol. 189, no. 1-2, pp. 241-248, 2011.

[17] Q. Zhang, S. Zhang, S. Chen, P. Li, T. Qin, and S. Yuan, "Preparation and characterization of a strong basic anion exchanger by radiation-induced grafting of styrene onto poly(tetrafluoroethylene) fiber," Journal of Colloid and Interface Science, vol. 322, no. 2, pp. 421-428, 2008.

[18] C. Xiong and C. Yao, "Preparation and application of acrylic acid grafted polytetrafluoroethylene fiber as a weak acid cation exchanger for adsorption of Er(III)," Journal of Hazardous Materials, vol. 170, no. 2-3, pp. 1125-1132, 2009.

[19] Z. Ding, Y. Dong, and B. Li, "Preparation of a modified PTFE fibrous photo-Fenton catalyst and its optimization towards the degradation of organic dye," International Journal of Photoenergy, vol. 2012, Article ID 121239, 8 pages, 2012.

[20] Y. Dong, W. Dong, Y. Cao, Z. Han, and Z. Ding, "Preparation and catalytic activity of $\mathrm{Fe}$ alginate gel beads for oxidative degradation of azo dyes under visible light irradiation," Catalysis Today, vol. 175, no. 1, pp. 346-355, 2011.

[21] J. Feng, X. Hu, and P. L. Yue, "Effect of initial solution $\mathrm{pH}$ on the degradation of Orange II using clay-based Fe nanocomposites as heterogeneous photo-Fenton catalyst," Water Research, vol. 40, no. 4, pp. 641-646, 2006.

[22] A. C.-K. Yip, F. Leung-Yuk Lam, and X. Hu, "Novel bimetallic catalyst for the photo-assisted degradation of Acid Black 1 over a broad range of pH," Chemical Engineering Science, vol. 62, no. 18-20, pp. 5150-5153, 2007.

[23] W. S. Perkins, Textile Coloration and Finishing, Chinese notation edition authorized by Carolina Academic Press, China Textile Press, Beijing, China, 2004.

[24] Y. Dong, L. He, Q. Wang, M. Yang, R. Qi, and K. Li, "Effect of inorganic salts on ferric oxalate-induced decomposition of $\mathrm{CI}$ Acid Black 234 under different weather conditions," Coloration Technology, vol. 124, no. 1, pp. 19-26, 2008.
[25] Z. Ding, Y. Dong, B. Li, and M. Li, "Preparation of grafted PTFE fiber metallic complexes and their photocatalytic degradation abilities," Acta Physico-Chimica Sinica, vol. 29, no. 1, pp. 157-166, 2013.

[26] J. Feng, X. Hu, P. L. Yue, H. Y. Zhu, and G. Q. Lu, “Degradation of azo-dye orange II by a photoassisted Fenton reaction using a novel composite of iron oxide and silicate nanoparticles as a catalyst," Industrial and Engineering Chemistry Research, vol. 42, no. 10, pp. 2058-2066, 2003. 

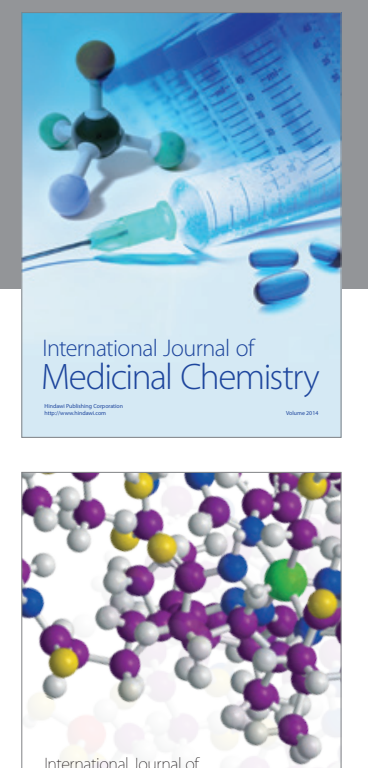

\section{Carbohydrate} Chemistry

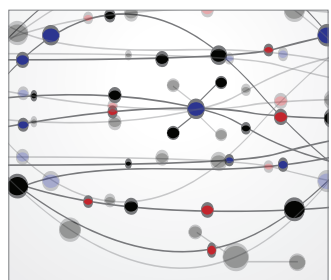

The Scientific World Journal
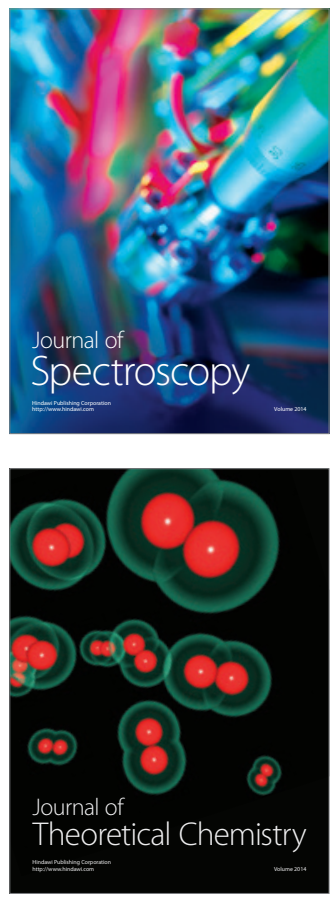
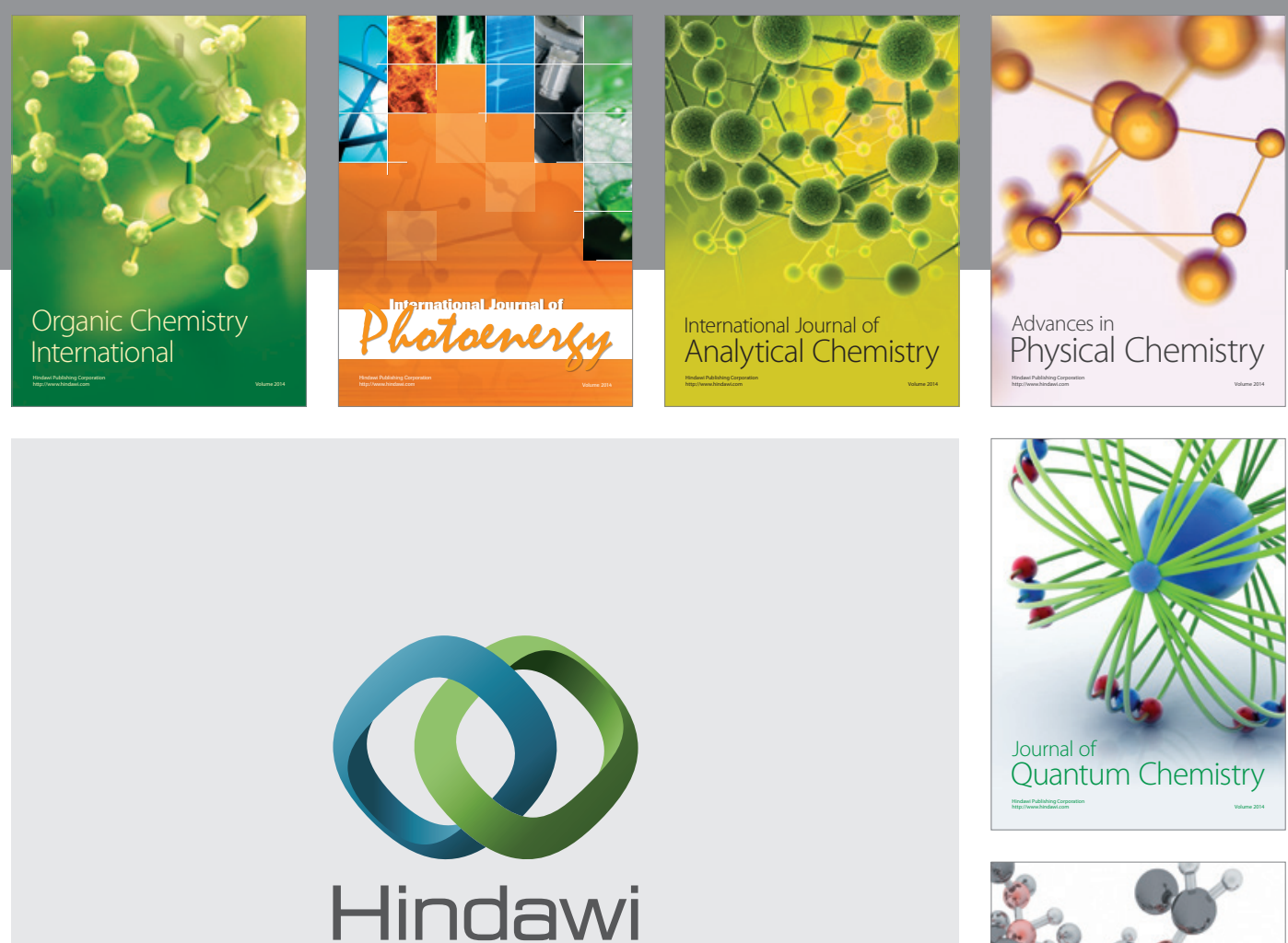

Submit your manuscripts at

http://www.hindawi.com

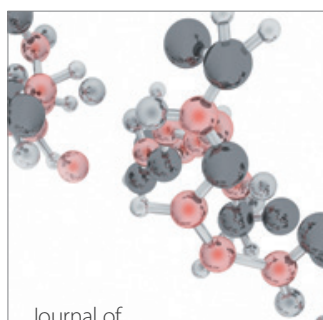

Analytical Methods

in Chemistry

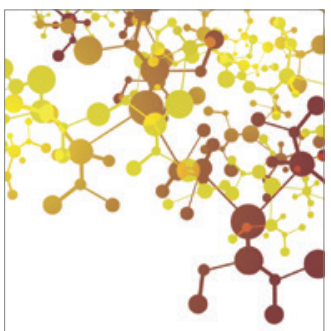

Journal of

Applied Chemistry

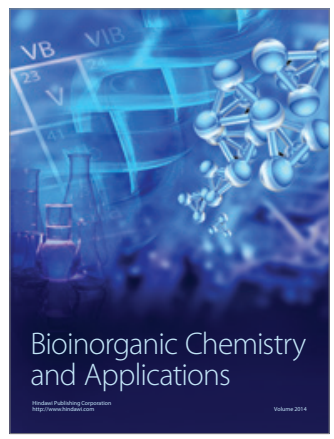

Inorganic Chemistry
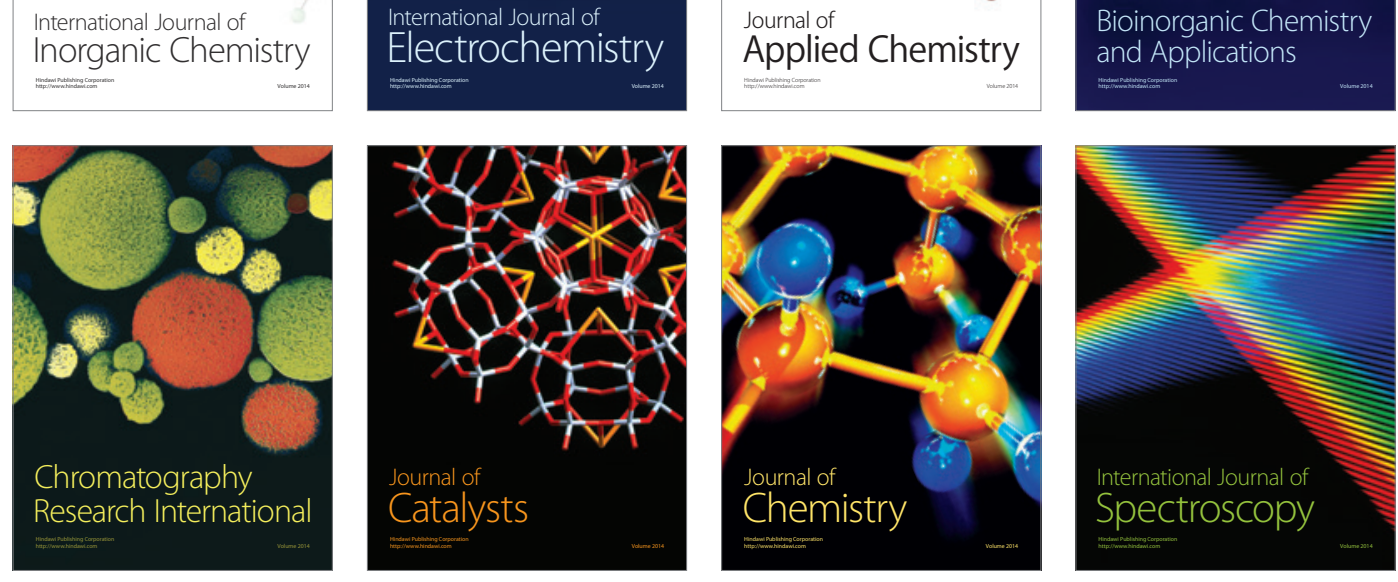